as new resources become available locally. ${ }^{29}$ For example, a number of future enhancements are already envisaged involving the inclusion of ideal body weight on the general practitioner review forms and an option for general practitioners to request review by a diabetes education nurse. Requests for intraocular pressure measurement may be added to the optical review forms. In July 1993 payments to general practitioners for disease management clinics will stop completely. In the case of non-insulin treated patients the health care objectives which practices will then have to meet in order to qualify for diabetic care payments could be met by prompting structured care as in Islington. Expansion of this pilot scheme into a district service is planned.

The development of diabetic shared care in Islington was supported by an Appeal Trust research fellowship to Dr B Hurwitz from the Rockefeller and endowments committee of the school of medicine, University College London. A development project grant from the British Diabetic Association and funds from the Greater London Enterprise Board of the GLC and the London Residuary Body supported this study. Annette Yiannaki, of the department of optometry and visual science, City University, interviewed all the optometrists. Rachel Pearce, of the clinical operational research unit, University College London, advised on data collection and performed much of the statistical analysis. We thank all the patients, general practitioners, and optometrists who participated.

1 Day JH, Humphreys SH, Alban-Davies H. Problems of comprehensive shared diabetes care. $B M \mathcal{F}$ 1987;294:1590-2.

2 Hayes TM, Harries J. Randomised controlled trial of routine hospital care versus routine general practice care for type II diabetics. BMF 1984;289: $728-30$.

3 Singh BM, Holland MR, Thorn PA. Metabolic control of diabetes in general practice clinics: comparison with a hospital clinic. BMF 1984;289:726-8.

Malins JM, Stuart JM. Diabetic clinic in a general practice. BMF 1971 ;iv: 161 .

5 Thorn PA, Russell RG. Diabetic clinics today and tomorrow: miniclinics in general practice. $B M \mathcal{F}$ 1973;ii:534-6.

6 Doney $\mathrm{BJ}$. An audit of the care of diabetes in a group practice. $f \mathrm{R}$ Coll Gen Pract 1976;26:734-42.
7 Hill RD. Community care service for diabetics in the Poole area. BMJ 1976;i:1137-9.

8 Dornan C, Fowler G, Mann JL, Markus A, Thorogood MA. A community study of diabetes in Oxfordshire. $7 \mathrm{R}$ Coll Gen Pract 1983;33:151-5.

9 Wilkes E, Lawton EE. The diabetic, the hospital and primary care. $f R$ Coll Gen Pract 1980;30:199-206.

10 Waine C. Why not care for your diabetic patients? London: Royal College of General Practitioners, 1986.

11 Tasker PRW. Is diabetes a disease for general practice? Practical Diabetes 1984;1:21-4.

12 Williams DRR, Munroe C, Hospedales CJ, Greenwood RH. A three-year evaluation of the quality of diabetes care in the Norwich community care scheme. Diabetic Med 1989;7:74-9.

13 Kopelman P, Keable-Elliott D. An inner city district diabetic care scheme. Diabetic Med 1990;8:558-61.

14 Burns-Cox CJ, Dean Hart JC. Screening of diabetics for retinopathy by ophthalmic opticians. BMf 1985;290:1052-4.

15 Hill RD. Screening for diabetic retinopathy at primary health care level. Diabetologia 1981;20:670.

16 Buxton MJ, Sculpher MJ, Ferguson BA, Humphreys JE, Altman JFB, Spiegelhalter DJ, et al. Screening for treatable diabetic retinopathy: comparison of different methods. Diabetic Med 1991;8:371-7.

17 Finlay R, Griffiths J, Johnson G, Law D. Can general practitioners screen their own patients for diabetic retinopathy? Health Trends 1991:23:104-5.

18 Sculpher MJ, Buxton MJ, Ferouson BA, Humphreys JE, Alman JFB, Spienter DJ, at. A rative costeffectiveness analysis of differB, Spiegelhalter DJ, et al. A relative cost-effectiveness analysis of differen

19 Rohan TE, Frost CD, Wald NJ. Prevention of blindness by screening for diabetic retinopathy: a quantitive assessment. BMF 1989;299:1198-201.

20 Kritzinger EE, Taylor KG. Diabetic eye disease, an illustrated guide to diagnosis and management. Lancaster: MTP Press, 1984.

21 Lindley DV, Scott WF. New Cambridge elementary statistical tables. Cambridge: Cambridge University Press, 1984:table 27.

22 Yiannaki A. Optometric screening for diabetic retinopathy in the community (BSc dissertation). London: Department of Optometry and Visual Science, City University, 1989:149, appendices.

23 Hammersley MS, Holland MR, Walford S, Thorn PA. What happens to defaulters from a diabetic clinic? $B M \mathcal{F} 1985 ; 291: 1330-2$.

24 Porter AMD. The Kirkcaldy community care project. Edinburgh: Department of General Practice, University of Edinburgh, 1979:75, appendices.

25 Kemple TJ, Hayter SR. Audit of diabetes in general practice. $B M \mathcal{J}$ $1991 \cdot 302: 451-3$.

26 Yudkin JS, Boucher BJ, Schopflin KE, Harris BJ, Clagg HR, Whyte NJD et al. The quality of diabetic care in a London health district. $f$ Epidemiol Community Health 1980;34:277-80.

27 Irving J, Casement S, Holme $Q$. A 'non-clinic' system of care for non-insulindependent diabetics in general practice. Practical Diabetes 1988;51:125-8.

28 Foulkes A, Kinmonth A, Frost S, MacDonald A. Organised personal care - an effective choice for managing diabetes in general practice. $\mathcal{F} R$ Coll Gen Prac 1989;39:444-7.

29 Haines A, Feder G. Guidance on guidelines. BMJ 1992;305:785-6.

(Accepted 22 December 1992)
University of Nottingham Medical School, Queen's Medical Centre,

Nottingham NG7 2UH

Mike Pringle, senior lecturer

in general practice

Carol Stewart-Evans,

research associate, department

of general practice

Carol Coupland, lecturer in

medical statistics, department

of public health medicine and epidemiology

Idris Williams, professor of

general practice

Simon Allison, consultant

physician, department of

medicine

Jennifer Sterland, research nurse, department of general practice

Correspondence to:

Dr Pringle.

BMF 1993;306:630-4

\title{
Influences on control in diabetes mellitus: patient, doctor, practice, or delivery of care?
}

\author{
Mike Pringle, Carol Stewart-Evans, Carol Coupland, Idris Williams, Simon Allison, \\ Jennifer Sterland
}

\section{Abstract}

Objective-To assess patient, doctor, practice, and process of care variables for their effect on glycaemic control in diabetes mellitus, and to quantify their relative effects.

Design-Search of general practice medical records, patient questionnaires and examination, doctor questionnaire, videotaping and analysis of consultations, and practice questionnaire.

Setting-12 practices with 32 participating general practitioners in Nottinghamshire.

Subjects-318 patients randomly selected from those with diabetes in each practice, 10 for each participating doctor.

Main outcome measure-Glycaemic control as measured by random glycated haemoglobin $A_{1 c}$ estimation (random haemoglobin $A_{1}$ measurement).

Results-Glycaemic control was significantly related to the disease process as measured by years since diagnosis, treatment group, and number of diabetes related clinical events. Females had significantly worse control than males. Other patient factors, such as age, social class, lifestyle, attitudes, satisfaction, and knowledge, had no association with glycaemic control. Of all the doctor factors examined, only doctors who professed a special interest in diabetes achieved significantly better glycaemic control. Bigger and better equipped practices and those with a diabetic miniclinic had patients with significantly better glycaemic control, as did those with access to dietetic advice. Patients attending hospital clinics had worse glycaemic control, but this seemed to be attributable to the case mix and practice characteristics. Shared care did not contribute to the multiple linear regression model.

Conclusion-Glycaemic control among diabetic patients in the community is related to such factors as treatment group, sex, and years since diagnosis; it is also related to the organisation and process of care. The findings support concentrating diabetic care on partners with special interests in diabetes in well equipped practices with adequate dietetic support.

\section{Introduction}

The age adjusted prevalence of diagnosed diabetes mellitus is between $1.01 \%$ and $1.04 \%^{2}$ in white people in the United Kingdom, with higher rates among some ethnic minorities. ${ }^{3}$ There is evidence that good 
glycaemic control reduces the risk of diabetic complications that can be disabling or fatal. ${ }^{4-7}$

These two facts mean that diabetes is both a common and important clinical condition. They also mean that hospital care for all patients with diabetes is impracticable but that care in general practice must be sufficient to maximise glycaemic control. In 1980 Wilkes and Lawton showed that, though care in general practice was popular with patients, the process of care and disease control were poor. ${ }^{8}$ These findings were repeated throughout the early 1980s in Britain ${ }^{10}$ and abroad $^{11}$ as structured hospital care was compared with unstructured primary care.

As the general strategy for care was refined, ${ }^{12}$ so the need for structured care in general practice was recognised ${ }^{13-16}$ and shown to offer improved glycaemic control, ${ }^{17}$ comparable with that in hospital clinics. ${ }^{18}$ Many general practitioners, however, continue to offer low levels of supervision, ${ }^{19}$ and diabetic miniclinics are still offered in only a minority of practices. ${ }^{20}$

The organisation of care is not the only possible influence on glycaemic control. For patients psychosocial factors, ${ }^{21}$ life events, ${ }^{22}$ the locus of control, ${ }^{23}$ and patient knowledge ${ }^{24}$ have all been explored. The doctors' knowledge, ${ }^{25}$ health beliefs, ${ }^{26}$ and personality ${ }^{21}$ have all been postulated as influences on control, while there is an implicit assumption in the teaching of consultation skills that doctor behaviours affect outcomes such as glycaemic control. ${ }^{27}$ Studies which look at individual factors, however, often fail to show substantial effects and sometimes do not put the importance of that factor into true perspective. ${ }^{21}$

This study was designed to look at an array of possible influences on diabetic control in a group of diabetic patients in the community in order to identify which factors influenced glycaemic control and to quantify the relative contribution of each.

TABLE I-Variables examined and their source

\begin{tabular}{|c|c|}
\hline Variable & Source \\
\hline \multicolumn{2}{|l|}{ Glycaemic control } \\
\hline Random glycated haemoglobin (random haemoglobin $A_{1}$ estimation) & Patient's blood \\
\hline \multicolumn{2}{|c|}{ Factors examined for influence on glycaemic control } \\
\hline \multicolumn{2}{|l|}{ Patient factors: } \\
\hline Treatment group & General practice medical records \\
\hline Age and sex & General practice medical records \\
\hline Years since diagnosis & General practice medical records \\
\hline No of diabetes related clinical events in past 10 years & General practice medical records \\
\hline Socioeconomic group & Patient questionnaire \\
\hline Lifestyle - smoking, alcohol & Patient questionnaire \\
\hline Satisfaction & Patient questionnaire \\
\hline Attitudes to diabetes & Patient questionnaire \\
\hline Knowledge of diabetes & Patient questionnaire \\
\hline Health locus of control & Patient questionnaire \\
\hline Nottingham health profile & Patient questionnaire \\
\hline \multicolumn{2}{|l|}{ General practitioner factors: } \\
\hline Age and sex & General practitioner questionnaire \\
\hline Attitudes to diabetes & General practitioner questionnaire \\
\hline Knowledge of diabetes & General practitioner questionnaire \\
\hline Consultation style & TIMER analysis ${ }^{\star}$ of 10 consultations \\
\hline Personality & Cattell $16 \mathrm{PF}$ questionnaire $\star$ \\
\hline \multicolumn{2}{|l|}{ Practice factors: } \\
\hline Equipment, staff, and facilities & Practice questionnaire \\
\hline Practice protocol for diabetes & Practice questionnaire \\
\hline Practice diabetic clinic & Practice questionnaire \\
\hline \multicolumn{2}{|l|}{ Process of care: } \\
\hline Shared care status & General practice medical records \\
\hline No of consultations & General practice medical records \\
\hline Content of diabetic review in past 14 months & General practice medical records \\
\hline Health workers seen & Patient questionnaire \\
\hline
\end{tabular}

$\star$ See text.

TABLE II -Distribution of study practices according to partnership size and training and teaching

\begin{tabular}{lcccc}
\hline Partnership size & No of practices & $\begin{array}{c}\text { Average list size per } \\
\text { partner }\end{array}$ & $\begin{array}{c}\text { No providing } \\
\text { vocational } \\
\text { training }\end{array}$ & $\begin{array}{c}\text { No providing } \\
\text { undergraduate } \\
\text { teaching }\end{array}$ \\
\hline Singlehanded & 3 & 3033 & & 1 \\
Two partners & 3 & 1933 & 3 & 1 \\
Four partners & 5 & 1805 & 3 & 5 \\
Nine partners & 1 & 1850 & 3 & \\
\hline Total & 12 & 1933 & & \\
\hline
\end{tabular}

\section{Method}

A number of possible influences on control and methods for measuring each were identified (table I). Eighteen Nottinghamshire practices were randomly selected from the family practitioner committee (now family health services authority) list and invited to take part in the study. Twelve practices agreed to participate, one as a pilot practice (in which only two of the four partners were involved). In one participating practice one general practitioner declined to take part in the study and a further three were excluded - two because they had joined their practices within the previous six months and one because he left the practice during the study. This gave 32 participating general practitioners. Of these general practitioner principals, $25(78 \%)$ were male; $14(44 \%)$ were under $40,14(44 \%)$ were aged $40-59$, and four $(13 \%)$ were aged 60 or over. The distribution of partnership size and teaching commitment is shown in table II. These characteristics are similar to the characteristics of Nottinghamshire practices as a whole.

All participating practices completed a practice questionnaire and each participating doctor completed two general practitioner questionnaires which included five multiple choice questions, each with five stems, from recent MRCGP examinations to test their knowledge of diabetes. Each doctor completed the Cattell 16 personality factor (16PF) questionnaire..$^{28}$

For each participating doctor a routine surgery was chosen at random and the consultations with 10 consecutive consenting patients video recorded. Patients with diabetes were not excluded, but most patients were not diabetic. These consultations were analysed by TIMER, ${ }^{29}$ a methodology which quantifies the time allocated to five physical, nine verbal, and four secondary task activities. Ten unselected consultations are reportedly sufficiently accurate to characterise an individual doctor's consulting style by using TIMER. ${ }^{30}$

A list of all patients with a diagnosis of diabetes mellitus was identified for each practice by using a preexisting disease register, a repeat prescribing register, an examination of all repeat prescription requests over two months, or, in one practice, a manual search through all the medical record envelopes. The prevalence of diabetes thus established ranged from $0.92 \%$ to $1.71 \%$, with seven practices grouped in the range $1 \cdot 11 \%$ to $1 \cdot 31 \%$ around the mean of $1 \cdot 28 \%$. All patients aged under 18, with dementia or severe psychiatric illness, in institutions, or who had registered with the practice within the previous year were excluded from the study.

From the remainder, patients representing 12 times the number of participating general practitioners in the practice were selected randomly. Ten patients for each general practitioner were approached, and the others were reserved to replace any patients who declined to take part. On two occasions 12 patients were insufficient as only nine consented, giving an overall number of 318 patients. The number of patients was chosen to give a sample size of at least 300 , which was calculated to have a $90 \%$ power to detect a $1 \%$ difference in glycated haemoglobin (haemoglobin $\mathbf{A}_{1 \mathrm{c}}$ ) concentration at the $5 \%$ level between two groups of equal size, given a standard deviation of $2 \cdot 5 \%$.

A written invitation was sent to 10 patients for each doctor asking them to participate in the study. Sixteen patients refused, of whom 14 were replaced by another patient from the 12 for each doctor. Those who agreed were visited at home, where, after giving informed consent, they completed a series of questionnaires and had blood taken by the research nurse. The general practitioner's medical record envelope was searched and variables concerning the process of care recorded. The percentage of glycated haemoglobin in the random sample taken in the visit to the patient's home (random 
haemoglobin $A_{1}$ estimation) was used to measure the level of glycaemic control for each patient. All samples were processed by a single laboratory. Each practice was given the results of the study for all their participating patients after the study had been completed in that practice. No practice audits of diabetic care were under way during the study.

The data were entered by using the scientific information retrieval program and analysed on SPSS/PC+ . The unpaired $t$ test was used to compare the mean levels of diabetic control in two groups by means of a two sided test. One way analysis of variance was used to compare the mean levels of diabetic control in three or more groups. A multiple linear regression model was used to assess the independent effects on diabetic control of those variables studied. A stepwise procedure was used, with the inclusion criteria set at $\mathrm{p}=0.05$ and the exclusion criteria set at $\mathrm{p}=0 \cdot 1$. Dummy variables were created for categorical variables. Residuals were used to check the assumptions of the model.

\section{Results}

Results were obtained for 318 study patients. A blood specimen was unobtainable from 10 patients, so

TABLE III-Glycaemic control as measured by random haemoglobin $A_{1}$ estimation and its relation to patient, doctor, and practice variables $(n=308)$

\begin{tabular}{|c|c|c|c|}
\hline & No & $\begin{array}{c}\text { Mean (SD) } \\
\text { haemoglobin } \\
A_{1}(\%)\end{array}$ & \\
\hline \multicolumn{4}{|c|}{ Patient variables } \\
\hline Treatment group: & & & \multirow{4}{*}{$F=9.65 ; \mathrm{p}<0.0001$} \\
\hline Insulin & 86 & $11 \cdot 0(2 \cdot 4)$ & \\
\hline Oral hypoglycaemics & 155 & $10 \cdot 8(2 \cdot 8)$ & \\
\hline Diet alone & 67 & $9 \cdot 3(2 \cdot 2)$ & \\
\hline \multicolumn{4}{|l|}{ Sex: } \\
\hline Male & 165 & $10 \cdot 2(2 \cdot 6)$ & \multirow{2}{*}{$t=2 \cdot 38 ; \mathrm{p}=0.02$} \\
\hline Female & 143 & $10.9(2 \cdot 7)$ & \\
\hline \multicolumn{4}{|l|}{ Years since diagnosis: } \\
\hline $\begin{array}{l}\leqslant 7 \\
>7\end{array}$ & 153 & $10 \cdot 1(2 \cdot 7)$ & $t=2.80 ; \mathrm{p}=0.005$ \\
\hline \multicolumn{4}{|l|}{ No of diabetes related events: } \\
\hline $\begin{array}{l}0 \text { or } 1 \\
\geqslant 2\end{array}$ & $\begin{array}{l}146 \\
162\end{array}$ & $\begin{array}{l}10 \cdot 1(2 \cdot 5) \\
10 \cdot 9(2 \cdot 7)\end{array}$ & $t=2 \cdot 58 ; \mathrm{p}=0.01$ \\
\hline \multicolumn{4}{|c|}{ Does patient find it "very easy" to control diabetes? } \\
\hline Yes & 149 & $10 \cdot 2(2 \cdot 5)$ & \multirow{3}{*}{$t=2 \cdot 26 ; \mathrm{p}=0 \cdot 02$} \\
\hline No & 139 & $11 \cdot 0(2 \cdot 8)$ & \\
\hline Data missing & 20 & & \\
\hline \multicolumn{4}{|c|}{ Does patient have enough practical help? } \\
\hline Yes & 261 & $10 \cdot 4(2 \cdot 5)$ & \multirow{3}{*}{$t=3.74 ; \mathrm{p}<0.001$} \\
\hline No & 28 & $12 \cdot 7(3 \cdot 2)$ & \\
\hline Data missing & 19 & & \\
\hline \multicolumn{4}{|c|}{ General practitioner variables } \\
\hline \multicolumn{4}{|c|}{ Does general practitioner have special interest in diabetes? } \\
\hline Yes & 56 & $9 \cdot 7(2 \cdot 3)$ & \multirow[t]{2}{*}{$t=2.61 ; \mathrm{p}=0.009$} \\
\hline $\begin{array}{l}\text { No } \\
\text { Data missing }\end{array}$ & 250 & $10 \cdot 7(2 \cdot 7)$ & \\
\hline \multicolumn{4}{|c|}{ Practice variables } \\
\hline \multicolumn{4}{|c|}{ No of items of equipment in practice: } \\
\hline$\leqslant 10$ & 135 & $10 \cdot 9(2 \cdot 7)$ & \multirow{2}{*}{$t=2 \cdot 48 ; \mathrm{p}=0.01$} \\
\hline$>10$ & 173 & $10 \cdot 2(2 \cdot 5)$ & \\
\hline \multicolumn{4}{|l|}{ No of partners in practice: } \\
\hline & 19 & $11 \cdot 3(3 \cdot 0)$ & \multirow{3}{*}{$F=3 \cdot 35 ; \mathrm{p}=0.04$} \\
\hline 2 or 4 & 240 & $10 \cdot 7(2 \cdot 7)$ & \\
\hline $9^{\star}$ & 49 & $9 \cdot 7(2 \cdot 2)$ & \\
\hline \multicolumn{4}{|l|}{ Access to community dietitian: } \\
\hline Yes & 49 & $9 \cdot 7(2 \cdot 2)$ & \multirow{2}{*}{$t=2 \cdot 39 ; \mathrm{p}=0.02$} \\
\hline No & 259 & $10 \cdot 7(2 \cdot 7)$ & \\
\hline Access to hospital dietitian: & & & \\
\hline Yes & 268 & $10 \cdot 3(2 \cdot 6)$ & $t=3.41 \cdot 0<0.001$ \\
\hline No & 40 & $11 \cdot 8(2 \cdot 7)$ & $t=3.41 ; \mathrm{p}<0.001$ \\
\hline Practice nurse with dietetic $s$ & & & \\
\hline Yes & 87 & $9 \cdot 7(2 \cdot 1)$ & $t=3.41 ; \mathrm{p}<0.001$ \\
\hline No $\ldots \ldots$ & 221 & $10 \cdot 8(2 \cdot 8)$ & \\
\hline Diabetic miniclinic in practi & & & \\
\hline Yes & 47 & $9 \cdot 7(2 \cdot 2)$ & $t=2 \cdot 21 ; \mathrm{p}=0.03$ \\
\hline No & 259 & $10 \cdot 7(2 \cdot 7)$ & \\
\hline Data missing & ss of $c a$ & e variable & \\
\hline Where patient seen: & & & \\
\hline $\begin{array}{l}\text { Attends only general } \\
\text { practitioner }\end{array}$ & 171 & $10 \cdot 1(2 \cdot 6)$ & \\
\hline Attends hospital (shared & & & $t=3.04 ; \mathrm{p}=0.003$ \\
\hline care) & 137 & $11 \cdot 0(2 \cdot 7)$ & \\
\hline
\end{tabular}

*Only five doctors in nine partner practice were eligible to take part in *Only five
study.
Diabetes related diagnoses and events recorded in past 10 years which were used to measure clinical status

Acute hypoglycaemia requiring medical intervention Acute hyperglycaemia requiring medical intervention Foot ulceration or amputation

Stroke or transient ischaemic attack

Myocardial infarction or angina

Heart failure

Hypertension

Claudication

Registered partially sighted or blind

Retinopathy or maculopathy

Nephropathy or urinary tract infection

Autonomic neuropathy

Peripheral neuropathy

that only 308 patients had a valid value for a random haemoglobin $\mathrm{A}_{1}$ estimation. This is the denominator used in the text and in table III unless otherwise specified. The random haemoglobin $A_{1}$ value was a continuous variable, which was shown in a histogram to be approximately normally distributed. The numbers of patients and mean random haemoglobin $A_{1}$ values with standard deviations are given in table III for those patient, general practitioner, and practice variables significantly associated with differences in glycaemic control.

\section{PATIENT FACTORS}

Sixty seven patients $(22 \%)$ were treated with diet alone, and they had significantly lower mean random haemoglobin $A_{1}$ values compared with the $155(50 \%)$ receiving oral hypoglycaemic therapy and the $86(28 \%)$ taking insulin. The difference in mean random haemoglobin $A_{1}$ values between the insulin and oral hypoglycaemic groups was small and not significant.

Compared with the 165 males, the 143 female patients had a significantly higher mean random haemoglobin $A_{1}$ value despite having had diabetes for fewer years (females: mean 9.5 years; males: mean 10.3 years; $p=0 \cdot 36)$. Though the patient's age had no significant effect on control, years since diagnosis did. Those patients diagnosed within the previous seven years $(n=153 ; 50 \%)$ had significantly better control than those diagnosed eight or more years previously.

To measure the long term consequences of diabetes and their relation to glycaemic control the presence of diabetes related complications within the past 10 years was recorded from the patient's general practice records. By totalling the number of such problems (listed in the box) a total score with a maximum of 13 was derived. The number of these diabetes related problems was correlated with the random haemoglobin $A_{1}$ value (Spearman's rank correlation, $r=0 \cdot 17$; $p=0.004)$. When those patients with none or one recorded diabetes related problem were compared with those with two or more problems they were found to have significantly better control.

The levels of smoking, alcohol consumption, and socioeconomic group, which were all asked for in the patient questionnaire, had no significant effect on control. The patients expressed high levels of satisfaction with the care they were receiving, including the number of blood tests, the thoroughness of examination, the general practitioner's willingness to discuss diabetes, their involvement in decision making, ease of contact, and with general practice care overall (86-96\% of patients answering "satisfied" or "very satisfied"). Of the 145 patients attending a hospital diabetic clinic, $101(70 \%)$ said they were "very satisfied" with their overall hospital care. No significant relation between control and satisfaction was shown.

Ten patients $(3 \cdot 2 \%)$ claimed that they had never 
been advised to check their urine, a further $39(13 \%)$ never checked their urine, and $53(17 \%)$ checked their urine less than weekly. The frequency of urine testing was not significantly related to control. The patients were asked how easy they found it to maintain good control. The 149 (48\%) who answered "very easy" were more likely than the others to have better control. The $28(9 \cdot 1 \%)$ patients who responded negatively to the question "do you feel you have had enough practical help and support recently?" had worse control than those answering affirmatively.

Eighty four patients $(27 \%)$ thought they ought to be looked after by both their general practitioner and the hospital, $138(45 \%)$ by their general practitioner alone, $54(17 \%)$ by the hospital alone, and $13(4 \cdot 2 \%)$ by a diabetes nurse (19 patients did not respond to this question). These and other questions on patient expectations showed no significant relation to control. Patient health status (as measured by the Nottingham health profile), health locus of control, and patient knowledge of diabetes were not significantly related to glycaemic control.

\section{GENERAL PRACTITIONER FACTORS}

Patients were asked to identify the general practitioner whom they regarded as their "usual general practitioner" for their diabetic care. That doctors' sex, age, years as a principal, training, or teaching and training activity were not shown significantly to influence their patients' diabetic control. Likewise, no significant correlations were detected between control and the doctor's personality, the doctor's diabetic knowledge, or doctor's consultation style. However, the $56(18 \%)$ patients of those doctors who professed a special interest in diabetes had a significantly lower mean random haemoglobin $A_{1}$ value (table III).

\section{PRACTICE FACTORS}

The practice questionnaires asked about the presence of 16 items of equipment on the premises. These ranged from a peak flow meter and a sphygmomanometer to oxygen and a defibrillator. When those patients attending a practice with more than 10 items $(n=173)$ were compared with those with 10 or fewer $(n=135)$ they showed significantly better diabetic control. The type of premises (practice owned, district health authority health centre, or rented) had no significant effect on control.

The prevalence of diabetic patients in each practice (which might be taken as an indication of commitment to case finding) was not significantly related to control, nor was the presence of a personal list system. There was a tendency for the patients in the bigger practices to have a lower random haemoglobin $A_{1}$ value (analysis of variance, $F=3 \cdot 35, \mathrm{df}=2305 ; \mathrm{p}=0 \cdot 04$ ).

Significantly lower random haemoglobin $A_{1}$ values were found among patients in practices with access to a community or hospital dietitian, with a practice nurse skilled in diabetic care, or which ran miniclinics. However, when the 181 patients in practices without any diabetic protocol were compared with the others no significant difference was shown.

\section{PROCESS OF CARE}

The search of the general practice medical record was used to categorise patients according to whether they attended the general practice only $(n=171 ; 56 \%)$ or whether they also attended the hospital $(n=137$; $44 \%$ ). The latter "shared care" group included 15 patients who thought that the main decisions concerning their diabetes were made in general practice.

Overall, the patients managed in general practice had significantly better control than those having shared care (table III). When the patients were ex- amined by treatment group $17(10 \%)$ patients in general practice were taking insulin, $105(61 \%)$ were taking oral hypoglycaemics, and $49(29 \%)$ were being treated by diet alone. This compared to $69(50 \%)$ taking insulin, 50 (36\%) taking oral hypoglycaemics, and $18(13 \%)$ on diet alone among the patients receiving shared care. The mean random haemoglobin $A_{1}$ values within treatment groups were lower, but not significantly so, in the general practice patients (insulin dependent $10 \cdot 2 \% \quad v 11 \cdot 2 \%, \mathrm{p}=0 \cdot 15$; oral hypoglycaemics $10 \cdot 6 \%$ v $1 \cdot 2 \%, \mathrm{p}=0 \cdot 17$; diet alone $9 \cdot 1 \% v$ $9 \cdot 9 \%, \mathrm{p}=0 \cdot 18)$.

The patients having shared care involving attendance at a hospital clinic were less likely to have access to a community dietitian $\left(\chi^{2}=44 \cdot 3, \mathrm{df}=1 ; \mathrm{p}<0.00001\right)$, a hospital dietitian $\left(\chi^{2}=6.9, \mathrm{df}=1 ; \mathrm{p}=0.008\right)$, or a practice nurse with dietetic skills $\left(\chi^{2}=18 \cdot 6, \mathrm{df}=1\right.$; $\mathrm{p}=0 \cdot 00003)$. They were less likely to have a general practitioner with an interest in diabetes $\left(\chi^{2}=21.7\right.$, $\mathrm{df}=1 ; \mathrm{p}<0.00001)$ or to attend a practice with a miniclinic $\left(\chi^{2}=42 \cdot 6, \mathrm{df}=1 ; \mathrm{p}<0 \cdot 00001\right)$. Indeed, only one patient registered with a practice with a diabetic miniclinic had shared care with the hospital.

There was no significant relation between diabetic control and the number of general practice consultations in the previous two years, either in total or for diabetes related reasons. Fourteen diabetes related examinations were looked for in the medical records, ranging from visual acuity and foot pulses to random blood sugar and urine analysis. The degree to which the patients had been screened was not significantly related to control.

\section{MULTIVARIATE ANALYSIS}

Table IV gives the results for multiple regression analysis using all the variables shown in this study to influence the random haemoglobin $A_{1}$ value. The six variables which were retained in the model accounted for $15.4 \%$ of the overall variation. Of these, two were not immutable patient characteristics-access to a hospital dietitian reduced the random haemoglobin $A_{1}$ value by a mean of $1.06 \%$, and the general practitioner having a special interest in diabetes reduced it by $0 \cdot 86 \%$.

TABLE IV-Multiple regression analysis showing variables independently influencing random haemoglobin $A_{1}$ value

\begin{tabular}{lrrc}
\hline & $\begin{array}{c}\text { Regression } \\
\text { coeficient }\end{array}$ & $\begin{array}{c}\text { Standard } \\
\text { error }\end{array}$ & p Value \\
\hline Variable & & & \\
Patient variables: & 10.51 & 0.59 & $<0.0001$ \\
Constant & 0.29 & 0.37 & 0.42 \\
Oral hypoglycaemics $v$ insulin & -0.97 & 0.46 & 0.04 \\
Diet alone $v$ insulin & 0.20 & 0.08 & 0.01 \\
No of diabetes related events & 0.72 & 0.28 & 0.01 \\
Female $v$ male & 0.04 & 0.02 & 0.04 \\
Years since diagnosis & -1.06 & 0.43 & 0.01 \\
Delivery of care variables: & & & \\
Access to hospital dietetian (yes $v$ no) & -1.06 & 0.38 & 0.02 \\
General practitioner interested in & -0.86 & & \\
$\quad$ diabetes (yes $v$ no) & & &
\end{tabular}

Variables explain $15.4 \%$ of variance in random haemoglobin $A_{1}$ values.

\section{Discussion}

It is impossible to achieve uniform and ideal control in every patient with diabetes. ${ }^{31}$ Some patients inevitably have better control than others, and some explanations for this are not amenable to change. For example, in this study the patients' sex and the length of time since diagnosis were both significantly associated with glycaemic control, as were the treatment group and number of diabetes related events in the previous 10 years.

However, other patient characteristics such as social class, age, smoking, alcohol intake, beliefs, satisfaction, and knowledge had no significant effect on control. If a cohort of patients with diabetes shows poor 
control this study has found little evidence that it should be attributed to factors specific to non-diabetic patients. This means that patient characteristics determined by the locality of a practice offer insufficient explanation for variation in control in those with diabetes.

Of all the doctor related factors examined, including personality, knowledge, and consultation style, only a special interest in diabetes was shown to be significantly associated with better control. As far as practice factors are concerned, patients registered with better equipped and larger practices had better control, as did those in practices with diabetic miniclinics. Those patients with access to dietitians - whether community or hospital dietitians or a practice nurse with dietetic skills - had better control. This evidence suggests that the organisation of care exerts a real influence on glycaemic control in diabetes.

Those patients attending general practice alone showed better control when compared with those having shared care with a hospital outpatient clinic. This runs counter to previous findings ${ }^{910} 18$ but there were many confounding variables. The treatment group mix was different in the hospital attenders, with an inevitable slant towards insulin dependency. The hospital attenders were more likely to be registered with a practice with no diabetic miniclinic and with a general practitioner with no special interest in diabetes. That the location of care is not a major determinant of glycaemic control was confirmed by the multiple linear regression (table IV), where shared care failed to contribute significantly to the model. This study does not, however, offer any support for the idea that diabetic patients looked after exclusively in primary care have worse glycaemic control and therefore a poorer prognosis.

The multiple linear regression analysis showed that access to a hospital dietitian gave the second largest contribution to explaining variance in the random haemoglobin $A_{1}$ value. This suggests that improving access to dietitians might be more efficacious than other changes. The other variable which was not patient defined and which contributed to the multiple regression model was being under the care of a general practitioner with a special interest in diabetes. This offers support for the idea (in those practices with at least one partner with a special interest in diabetes) of concentrating diabetic care on that partner, thus reinforcing that general practitioner's skills.

There are always risks when interpreting data from a descriptive study such as this one. An association between two variables does not infer causality and if one feature is associated with better glycaemic control it may not be the case that its widespread introduction will improve control. Bearing these caveats in mind, however, we may speculate from the evidence of this study on the changes that might improve the glycaemic control in patients with diabetes. This might occur if general practices encouraged a partner with a special interest in diabetes to care for their diabetic patients; if practices are well equipped as part of a commitment to quality of care; if the practice has access to dietitian services-most appropriately, perhaps, through the training of practice nurses in dietetics; and, in such well organised practices, if only those patients with special problems are referred to hospital diabetic clinics.

We thank the Medical Research Council for funding, Leslie Jenkins for early work on this project, Jim Pearson for statistical advice, the general practitioners and their staff who so willingly cooperated, and especially the patients who agreed to take part.

1 Gatling W, Houston AC, Hill RD. The prevalence of diabetes mellitus in a typical English community. $\mathcal{F} R$ Coll Physiciuns Lond 1985;4:248-50.

2 Neil HAW, Gatling W, Mather HM, Thompson AV, Thorogood M, Fowler GH, et al. The Oxford community diabetes study: evidence for an increase $\mathrm{GH}$, et al. The Oxford community diabetes study: evidence for an increase
in the prevalence of known diabetes in (ireat Britain. Diabetic Med in the prevalence
$1987 ; 4: 539-43$.

3 Mather HM, Keen H. The Southall diabetes survey: prevalence of known diabetes in Asians and Europeans. BMJ 1985;291:1081-4.

4 Cahill GF, Etzwiler DD, Freinkel N. "Control" and diabetes. N Engl Y Med 1976;294:1004.

5 Holman RR, Dornan TL, Mayon White V, Howard-Williams J, Orde-Pecker $\mathrm{C}$, Jenkins $\mathrm{L}$, et al. Prevention of deterioration of renal and sensory nerve function by more intensive management of insulin dependent diabetic patients. Lancet 1983;i:204-7.

6 Raskin P, Rosenstock J. Blood glucose control and diabetic complications. Ann Intern Med 1986;105:254-63.

7 McCance DR, Hadden DR, Atkinson AB, Archer DB, Kennedy L. Longterm glycaemic control and diabetic retinopathy. Lancet 1989;ii:824-8.

8 Wilkes $\mathrm{E}$, Lawton $\mathrm{E}$. The diabetic, the hospital and primary care. $\mathcal{J} R$ Coll Gen Pract 1980;30: 199-206.

9 Yudkin JS, Boucher BJ, Schopflin KE, Harris BT, Claff HR, Whyte NJ,

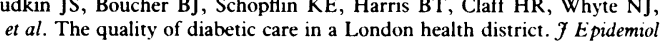
Community Med 1980;34:277-80.

10 Hayes TM, Harries J. Randomised controlled trial of routine hospital clinic care versus routine general practice care for type II diabetics. BMf 1984;289:728-30.

11 Basdevant A, Costagliola D, Lanoe JL, Goldgewicht C, Triomphe A, Metz F, $e t$ al. The risk of diabetic control: a comparison of hospital versus general practice supervision. Diabetologia 1982;22:309-14.

12 Watkins PJ. Diabetes mellitus. BMF 1983;286:269-71.

13 Thorn PA, Watkins PJ. Organisation of diabetic care. BMF 1982;285:787-9.

4 Gibbins RL, Saunders J. How to develop diabetic care in general practice. BMF 1988;297:187-9.

15 Foulkes A, Kinmonth A-L, Frost S, Macdonald D. Organised personal carean effective choice for managing diabetes in general practice. $\mathcal{J} R$ Coll Gen Pract 1989;39:444-7.

16 Wood $\mathrm{J}$. A review of diabetes care initiatives in primary care settings. Health Trends 1990;22:39-43.

17 Rutter G, Van Eyk J, de Nobel E, Beck M, Van der Velden H. Feasibility and effects of a diabetes type II protocol with blood glucose self-monitoring in general practice. Fam Pract 1990; 7:273-8

18 Singh BM, Holland MR, Thorn PA. Metabolic control of diabetes in general practice clinics: comparison with a hospital clinic. $B M \mathcal{Y}$ 1984;289:726-8.

19 Burrows PJ, Gray PJ, Kinmonth A-L, Payton DJ, Walpole GA, Walton RJ, et al. Who cares for the patient with diabetes? Presentation and follow-up in seven Southampton practices. I R Coll Gen Pract 1987;37:65-9.

20 Chesover D, Tudor-Miles P, Hilton S. Survey and audit of diabetes care in general practice in south London. Br f Gen Pract 1991;41:282-5.

21 Bradley C, Marteau TM. Towards an integration of psychological and medical perspectives of diabetes management. In: Alberti KGMM, Krall LP, eds. The diabetes annual. London: Elsevier, 1986.

22 Robinson N, Fuller JH. Role of life events and difficulties in the onset of diabetes meltitus. I Psychosom Res 1985;28:583-91.

23 Bradley C, Brewin CR, Gamsin DS, Moses JL. Development of scales to measure perceived control of diabetes mellitus and diabetes-related health beliefs. Diabetic Med 1984;1:213-8.

24 Hess GE, Davis WK. The validation of a diabetes patient knowledge test. Diabetes Care 1983;6:591-6.

25 Weinberger M, Cohen SJ, Mazzuca SA. The role of physician's knowledge and attitudes in effective diabetes management. Soc Sci Med 1984;19:965-9.

26 Kinmonth A-L, Marteau TM. Doctors' beliefs and the management of insulin dependent diabetes: implications for shared care. Family Pract 1989;6: 193-8.

27 Pendleton D, Schofield T, Tate P, Havelock P. The consultation: an approach to learning and teaching. Oxford: Oxford University Press, 1984.

28 Institute for Personality and Ability Testing. The administrator's manual for the 16 personality factor questionnaire. Chicago, III: IPAT, 1986

29 Pringle M, Robins S, Brown G. Timer: a new objective measure of consultation content and its application to computer assisted consultations. consultation content

30 Pringle $M$, Stewart-Evans $C$. Does awareness of being video recorded affect doctors' consultation behaviour? Br f Gen Pract 1990;40:455-8.

31 Pickup J. The pursuit of perfect control in diabetes. BMF 1988;297:929-30.

(Accepted 20 fanuary 1993) 